\title{
Interaction of Self-Assembled Monolayers of DNA with Electrons: HREELS and XPS Studies
}

\author{
Manuel Rei Vilar, ${ }^{\dagger}$ Ana M. Botelho do Rego, ${ }^{\ddagger}$ Ana M. Ferraria, ${ }^{\ddagger}$ Yvette Jugnet, ${ }^{\S}$ \\ Claude Noguès," Dana Peled," and Ron Naaman*,ll \\ ITODYS-CNRS, Université Paris Diderot, F-75005 Paris, France, CQFM, IST, Technical University of Lisbon, \\ P-1049-001 Lisboa, Portugal, IRCELYON-CNRS, 2, avenue A. Einstein F-69626 Villeurbanne cedex, France, \\ and Department of Chemical Physics, The Weizmann Institute, Rehovot 76100, Israel
}

Received: January 28, 2008

\begin{abstract}
We present results from high-resolution electron energy loss spectroscopy (HREELS) and XPS studies of self-assembled monolayers of DNA. The monolayers are well-organized and display sharp vibrational peaks in the HREEL spectra. The electrons interact mainly with the backbone of the DNA. The XPS results indicate that, in most of the samples studied, the phosphates on the DNA are not charged.
\end{abstract}

\section{Introduction}

Studying physical properties of biological systems is a challenge because it requires that microscopic details on the functioning of complex systems in an even more complex environment be obtained. Specifically, the detailed mechanism underlying electron-DNA interaction is difficult to address experimentally in vivo, where many parameters affect the interaction and where the electron energy is not well-defined. Therefore, only a limited amount of experimental information is available on oligomers that contain all of the building blocks of DNA. Among the few studies is an investigation of lowenergy electron damage to plasmid DNA deposited on a substrate and exposed to an electron beam. ${ }^{1,2}$ The electron interactions with the DNA and the fundamental mechanisms of damage to the DNA strand induced by the impact of lowenergy electrons were also examined. ${ }^{3,4}$ In an additional set of experiments involving thick layers of DNA condensed on a substrate, an electron beam impinged on the sample to produce ions. Those ions with sufficient kinetic energy escaped from the sample and were analyzed by mass spectrometry. Ion formation was studied as functions of both electron energy 5,6 and DNA bases. ${ }^{7}$ Other experiments have been performed on the building blocks of DNA in the gas ${ }^{8,9}$ and condensed ${ }^{10,11}$ phases. Additional gas-phase studies ${ }^{12-17}$ have shown that isolated nucleobases undergo dissociative electron attachment at subexcitation energies, which leads to the loss of neutral hydrogen.

It is now widely accepted that very low energy electrons (with energies below $4 \mathrm{eV}$ ) play an important role in the damaging of single- and double-stranded DNA (ss- and ds-DNA, respectively). The importance of this finding stems from the fact that irradiation of cells with high-energy photons or particles produces large amounts of very low energy electrons as the dominant secondary species (ca. $5 \times 10^{4}$ electrons per megaelectronvolt ${ }^{18}$ ). Therefore, it is most likely that low-energy

\footnotetext{
* To whom correspondence should be addressed. E-mail: ron.naaman@ weizmann.ac.il.

$\dagger$ Université Paris Diderot.

\$ Technical University of Lisbon.

$\S$ IRCELYON-CNRS

"The Weizmann Institute.
}

electrons contribute to DNA damage accumulation, which is one of the major sources of human cancer.

To study DNA damage induced by low-energy electrons mechanistically, it is essential to investigate the energetics and dynamics of the process. Recently, we introduced the possibility of investigating the interaction of electrons having well-defined energies with ss- and ds-DNA oligomers adsorbed on gold surfaces as organized self-assembled monolayers (SAMs). ${ }^{19,20}$ These systems were also used to obtain detailed information on the damage occurring in DNA by electrons. ${ }^{21,22}$

Here, we present results from a study of the inelastic scattering of low-energy electrons from self-assembled monolayers of DNA and from XPS studies on these layers. These studies provide information on the structure of the monolayers (their density, uniformity, thickness, etc.), as well as direct evidence on the role of the interaction of the backbone with the electrons as compared to that of the bases. In addition, insight into the charge state of the DNA in the layer is provided.

\section{Experimental Section}

A detailed experimental description is provided in the Supporting Information. In this section, we briefly describe the sample preparation and the experimental methods used.

DNA Sample Preparation and Adsorption. Self-assembled DNA monolayers on gold films were prepared by deposition of 3'-end-thiolated ss-DNA and ds-DNA of different sequences (Table 1). The details of the adsorption procedure are provided in the Supporting Information. In general, a $10 \mu \mathrm{M}$ solution of DNA (in $20 \mathrm{mM}$ Tris- $\mathrm{HCl}, \mathrm{pH} 7.5,0.4 \mathrm{M} \mathrm{NaCl}$ ) was spotted onto a clean gold slide for a given time, and humidity was controlled to avoid dryness. After adsorption at room temperature, the slide was rinsed in sterile deionized water to wash away excess DNA. The slide was then soaked in the same buffer while being shaken for $15 \mathrm{~min}$. This wash was then followed by $15 \mathrm{~min}$ of shaking in $20 \mathrm{mM}$ Tris- $\mathrm{HCl}(\mathrm{pH} 7.5,0.2 \mathrm{M} \mathrm{NaCl})$, 15 min of soaking in $20 \mathrm{mM}$ Tris- $\mathrm{HCl}(\mathrm{pH} \mathrm{7.5)}$, a thorough rinse in $20 \mathrm{mM}$ Tris- $\mathrm{HCl}(\mathrm{pH} 7.5)$, and a quick rinse in sterile deionized (Millipore) water to remove any excess salt left on the surface. The DNA was adsorbed on either n-type singlecrystal (111) silicon wafers or glass slides coated with gold.

Techniques. In a HREELS experiment, electrons are produced by a hot filament; energy is selected in a double-pass 
TABLE 1: DNA Oligomers Used in the Present Study

\begin{tabular}{ll}
\hline \multicolumn{1}{c}{ oligomer } & \multicolumn{1}{c}{ sequence } \\
\hline ss-GAT & HO-CATTAATGCTATGCAGAAAATCTTAG-C3-SH \\
ss-GTA-OH & HO-CTAAGATTTTCTGCATAGCATTAATG-C3-SH \\
ss-poly(C) & HO-CCCCCCCCCCCCC-C3-SH \\
ss-poly(A) & HO-AAAAAAAAAAAAAAAAAAAAAAAAAA-C3-SH \\
ss-poly(T) & HO-TTTTTTTTTTTTTTTTTTTTTT-C3-SH \\
ss-GCGT & HO-GCTGGATGGTATGGAGAAGATGTGCG-C3-SH \\
ss-CGAC & HO-CGCACATCTTCTCCATACCATCCAGC-C3-SH \\
ds-poly(T)/poly(A) & AAAAAAAAAAAAAAAAAAAAAAAAAA-OHSH-TTTTTTTTTTTTTTTTTTTTTTTT
\end{tabular}

$127^{\circ}$ cylindrical electrostatic condenser, the monochromator, and then focused onto the sample with a kinetic energy, $E_{\mathrm{p}}$, ranging from 0 to $10 \mathrm{eV}$. As all fields are conservative along the electron path, incident electron kinetic energy, $E_{\mathrm{p}}$, is defined by the difference between the electric potential of the filament and that of the surface of the sample. Electrons backscattered from the sample surface in a given direction, measured relatively to the normal to the surface, are then accelerated into an identical electrostatic condenser, the analyzer; selected in energy; and counted by an electron multiplier. The analyzer can be moved around the sample, enabling the angle profile to be recorded. In such a case, the intensity of scattered electrons undergoing a certain energy loss is represented as a function of the analyzed direction.

Vibrational and electronic losses were studied. Energy losses were recorded using three different HREEL spectrometers: A Leybold-Heraeus ELS-22 spectrometer and an LK Technologies ELS3000 spectrometer were used for the vibrational spectra, corresponding to energy losses lower than $0.5 \mathrm{eV}$. An LK2000R spectrometer was used for analyzing higher losses corresponding to excited electronic states. Spectral resolution better than 7 meV, taken as the full width at half-maximum (fwhm) of the elastic peak after reflection from the sample, was achieved using the LK Technologies ELS3000 spectrometer in the vibrational domain. Spectral resolution of the electronic losses was around $13 \mathrm{meV}$ for all samples. In all cases, the vacuum was better than $10^{-9}$ mbar. In fact, most of the DNA samples could be irradiated for several days without noticeable damage or charge effects.

The XP spectrometer used was an XSAM800 instrument (Kratos) operated in fixed analyzer transmission (FAT) mode, with a pass energy of $20 \mathrm{eV}$, nonmonochromatized $\mathrm{Al} \mathrm{K \alpha}$ X-radiation $(h v=1486.7 \mathrm{eV})$, and a power of $120 \mathrm{~W}$. Details on the data acquisition are included in the Supporting Information. Photoelectrons were analyzed at takeoff angles (TOAs) of $90^{\circ}$ and $30^{\circ}$ relative to the surface.

\section{Results}

HREELS Vibrational Excitation. In a HREELS experiment, the colliding electrons can lose energy either by short-range impact collisions or by long-range electron-dipole interactions. $^{23}$ The first mechanism is expected to become more efficient with increasing collision energy, whereas the excitation efficiency of the second mechanism decreases with increasing collision energy. Both of these processes can contribute concomitantly to the energy loss intensity, yielding a hybrid dependence on the incident electron energy. ${ }^{24}$ In any case, the initial kinetic energy of the electrons backscattered by the adsorbed molecules can be reduced through inelastic collisions with the molecular groups exposed to the vacuum. In the impact regime, the analysis method has analysis depths of less than 1 $\mathrm{nm}$, whereas dipolar collisions typically occur at distances of about $10 \mathrm{~nm}$. Hence, the nature of the interaction, revealed by
TABLE 2: Main Vibrations Corresponding to Characteristic Energy Losses in HREELS

\begin{tabular}{|c|c|}
\hline vibration $\left(\mathrm{cm}^{-1}\right)$ & assignment \\
\hline 565 & $\delta$ ring deformation \\
\hline $700-850$ & $\begin{array}{l}\text { symmetric } \mathrm{P}-\mathrm{O}-\mathrm{C} \text { stretching }+ \\
\mathrm{CH} \text { out-of-plane deformation }\end{array}$ \\
\hline 1089 & $\begin{array}{l}\mathrm{P}-\mathrm{OH} \text { stretching, asymmetric } \mathrm{P}-\mathrm{O}-\mathrm{C} \\
\text { and } \mathrm{C}-\mathrm{O}-\mathrm{C}\end{array}$ \\
\hline 1256 & $\mathrm{P}=\mathrm{O}$ stretching \\
\hline 1365 & $\mathrm{CH}\left(\mathrm{CH}_{3}\right)$ deformation \\
\hline 1447 & $\mathrm{CH}$ deformation \\
\hline 1651 & NH deformation \\
\hline 2920 & aliphatic $\mathrm{CH}$ stretching \\
\hline 3040 & aromatic $\mathrm{CH}$ stretching \\
\hline 3398 & $\mathrm{NH}$ stretching $+\mathrm{OH}$ stretching \\
\hline
\end{tabular}

the dependence of the cross sections on the incident electron energy, determines the distance of the incident electron with the excited group.

Figure 1 shows two spectra, one for a sample of adenine directly adsorbed on a gold substrate and the other one recorded from a single strand of 26 adenine bases, that is, an all-adenine oligomer [ss-poly(A), Table 1]. The incident electron energy was $5 \mathrm{eV}$, and the vibrational spectra did not vary when taken at specular or off-specular geometries.

Assignments of the spectral features appearing in the vibrational spectra presented in this study are listed in Table 2.25,26 One can see significant differences in the spectra of the directly adsorbed adenine and the oligomer film. Several characteristic bands of adenine that appear in the spectrum of adsorbed adenine are not present in the spectrum of the oligomer,

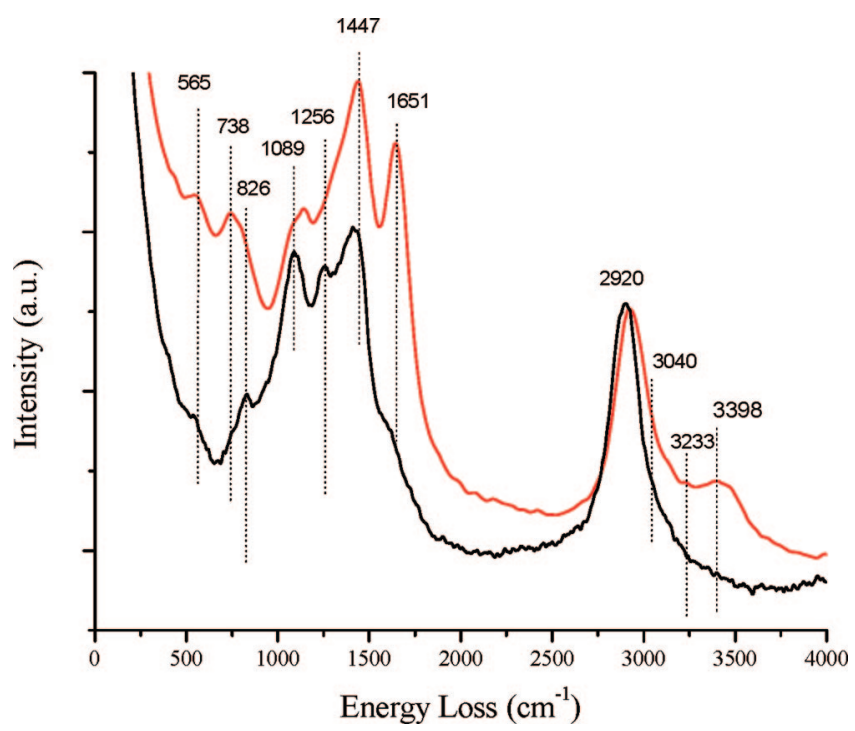

Figure 1. Comparison of HREEL spectra of a single strand of sspoly(A) (black) and a layer of adenine (red) deposited on gold. Spectra were recorded using $5 \mathrm{eV}$ electrons and an off-specular geometry with an incident angle of $60^{\circ}$ and an analysis angle of $30^{\circ}$. 


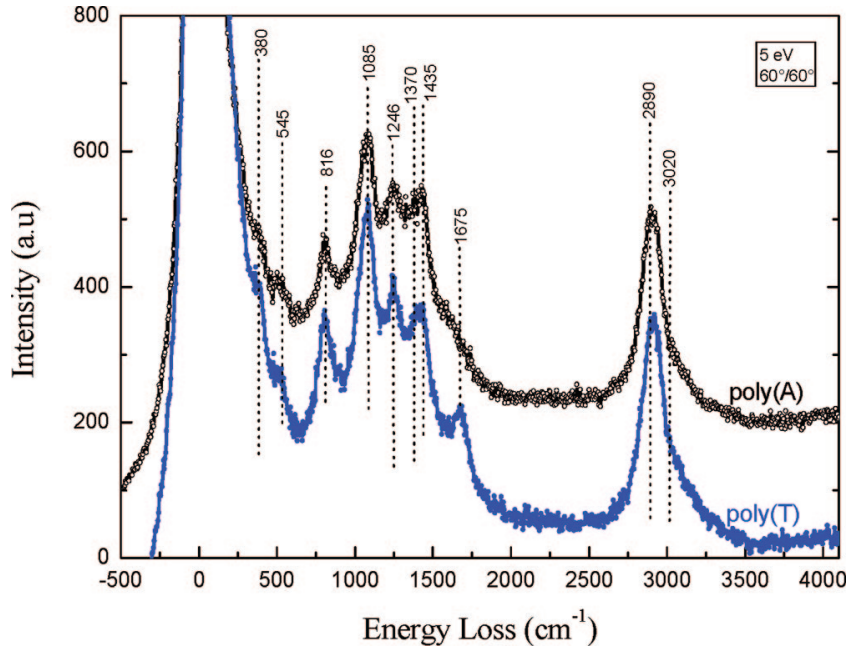

Figure 2. Comparison of HREEL spectra of samples ss-poly(A) (black) and ss-poly(T) (blue) of DNA monolayers deposited on gold surfaces recorded in a specular geometry $\left(60^{\circ} / 60^{\circ}\right)$ with an incident electron energy of $5 \mathrm{eV}$.

including the out-of-plane $\mathrm{CH}$ deformation at $738 \mathrm{~cm}^{-1}$ and the NH stretch at $3398 \mathrm{~cm}^{-1}$. The same is true for all of the other vibrations associated with the aromatic ring, which do not appear in the spectrum recorded with the oligomer film. For instance, the peak corresponding to the $\mathrm{CH}$ stretch is broader in the adenine spectrum, because it contains a perceptible contribution from the aromatic $\mathrm{CH}$ stretching. Another marked difference is observed in the peak around $1651 \mathrm{~cm}^{-1}$, corresponding to the $\mathrm{NH}$ symmetric bending motion, which is clearly observed in the adenine spectrum, but does not appear in the spectrum of the adsorbed oligomer.

Figure 2 presents spectra of two types of single-stranded DNA oligomers: an all-adenine strand [ss-poly(A)] and an all-thymine strand [ss-poly(T)]. Remarkably, both spectra exhibit outstanding resolution, despite the complexity of the molecular system. Most of the peaks appearing in Figure 1 can be recognized around the same positions. This observation reveals a smooth surface from which electrons are uniformly backscattered. The low elastic peak widths (fwhm), narrower than $55 \mathrm{~cm}^{-1}$, indicate that both molecular samples exhibit uniform and well-organized surfaces. ${ }^{27}$ No significant differences can be observed between the two spectra recorded from two different oligomers. Both spectra are mostly dominated by electron energy losses corresponding to the excitations of symmetric and asymmetric stretching modes of the phosphate and oxyribose groups between 800 and $1450 \mathrm{~cm}^{-1}$. In addition to these bands, characteristic of the backbone, the thymine sample clearly shows a sharp structure at $1675 \mathrm{~cm}^{-1}$ assigned to the $\mathrm{C}=\mathrm{O}$ stretching mode of the thymine rings. This band is associated with a long-range electron-dipole interaction, as shown in Figure 3. No excitation of any $\mathrm{SH}$ stretching is detected, thus confirming that all of the thiols were involved in the chemisorption of the strand on the gold substrate and that none were exposed to the vacuum.

On the other hand, spectra of the same samples recorded with incident energies higher than $5 \mathrm{eV}$ reveal the existence of a band around $3700 \mathrm{~cm}^{-1}$, likely produced by impact scattering (see Figure 3). This energy loss feature, assigned to the stretching mode of free or/and vicinal $\mathrm{OH}$ groups, confirms that hydroxyl groups present in the extremities of the DNA strands (see Table 1) are mostly exposed to the vacuum, standing on the extreme surface of the monolayer.

To unravel the nature of the electron interactions, spectra of different samples were recorded as a function of the incident

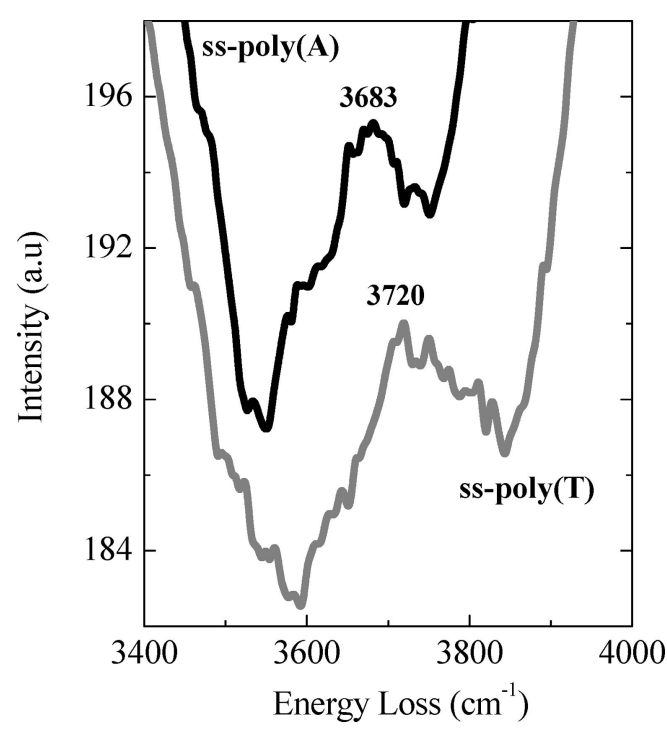

Figure 3. Domain of the $\mathrm{OH}$ stretching mode in spectra of ss-poly(A) (black) and ss-poly(T) (gray) characteristic of individual hydroxyl groups.

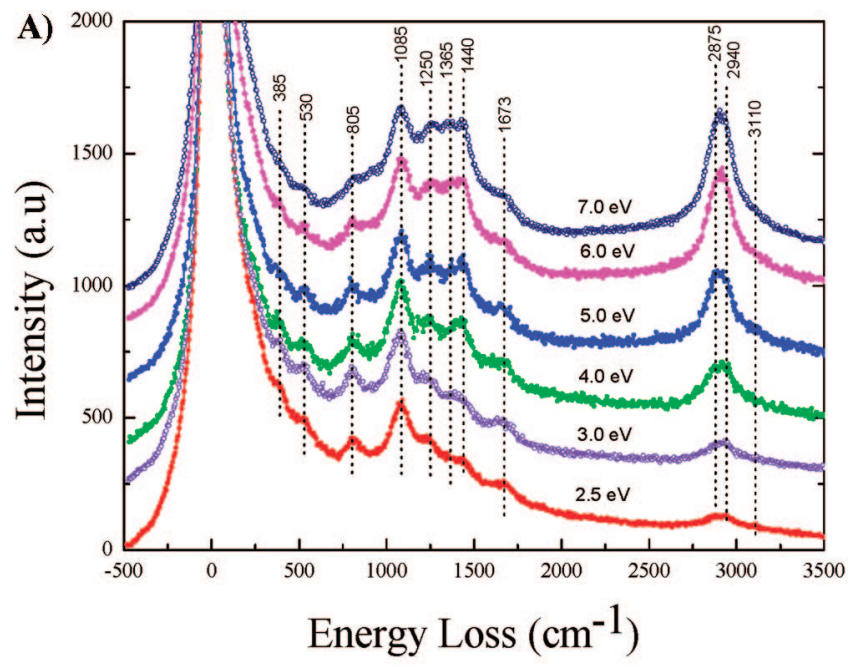

B)

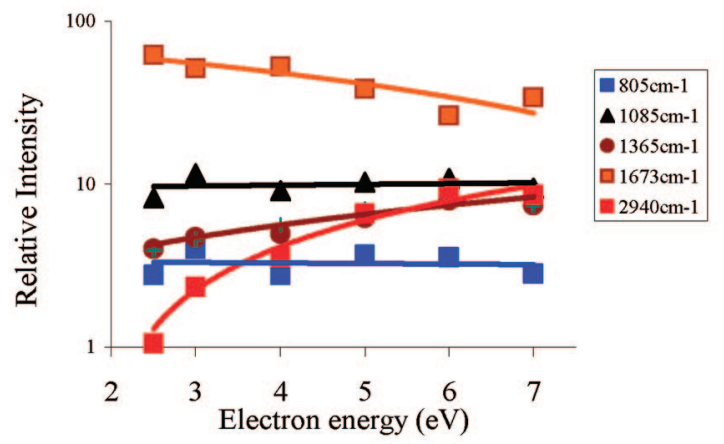

Figure 4. (A) Comparison of HREEL spectra of a double-stranded DNA monolayer [ds-poly(T)/poly(A)] deposited on a gold surface recorded in specular geometry $\left(60^{\circ} / 60^{\circ}\right)$ using different incident energies from 2.5 to $7 \mathrm{eV}$. The resolution is $\sim 7 \mathrm{meV}$. (B) Differential cross sections of the different components of the HREEL spectra as a function of the electron incident energy.

electron energy. Figure 4A presents the electron collision energy-dependent spectra of monolayers obtained with ds-DNA, made of oligomers containing 26 bases, all adenine and all thymine, poly(A)/poly(T). Spectra were recorded in a specular geometry, using electron incident energies varying from 2.5 to $7 \mathrm{eV}$. Again, as in the other spectra, the most intense peaks 


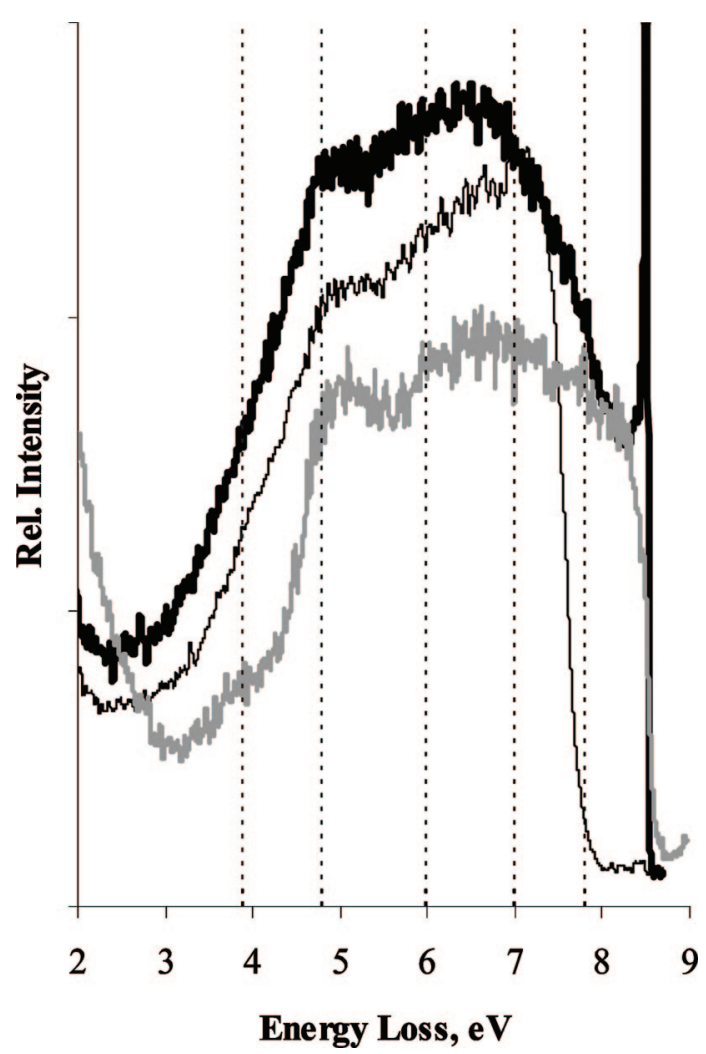

Figure 5. HREELS electronic spectra taken at a nominal energy of 8 $\mathrm{eV}$ for three different samples of DNA oligomers: ss-poly(A) (thin black), ss-poly(T) (thick black), and ds-poly(T)/poly(A) (gray). The incident and analysis angles relative to the normal to the sample were $60^{\circ}$ and $30^{\circ}$, respectively (off-specular).

characterize the interactions of the electrons with the backbone structure of the DNA strands. The intensity and area of each spectral component were determined using a Gaussian sum fitting where the bandwidth was fixed to the elastic peak fwhm. Component positions were consistent for all spectra and were considered as fixed parameters in the Gaussian analysis.

Figure 4B shows the energy dependence of some of the differential cross sections corresponding to some of the peaks present in spectra of Figure 4A, where the peak intensities are normalized to that of the elastic peak. Similar results were obtained for all samples. Whereas some of the differential cross sections slightly decrease with increasing collision energy (e.g., the peak at $1673 \mathrm{~cm}^{-1}$ ), others increase with the collision energy (e.g., the peaks at 1365 and $2940 \mathrm{~cm}^{-1}$ ), and some do not change (e.g., the peaks at 805 and $1085 \mathrm{~cm}^{-1}$ ). The results obtained are consistent with a picture where incident electrons mainly interact through both long- and short-range interactions with the backbone structure of the DNA strand, but mostly through long-range interactions with the bases.

HREELS Electronic Excitation. When the electron kinetic energy is high enough, it is possible to observe higher energy losses that correspond to electronic excitations. Figure 5 shows the electronic spectra recorded in an off-specular geometry at a nominal energy of $8 \mathrm{eV}$ for three different samples of DNA oligomers: ss-poly(A), ss-poly(T), and ds-poly(T)/poly(A). The threshold of the electronic excitations appears around $3.0 \pm 0.3$ $\mathrm{eV}$. The fitting of the spectra with a Gaussian sum is not straightforward. However, a good fitting could be obtained yielding Gaussians centered at 3.9, 4.8, 6.0, 7.0, and $7.8 \pm 0.2$ $\mathrm{eV}$. These values are in good agreement with those found in the electronic HREEL spectra of ultrathin layers containing aromatic groups assigned to a suite of triplet and singlet states. ${ }^{28}$
It should be noted here that triplet states can easily be excited by exterior electrons as the spin rule is not broken. Hence, the electronic part of the spectra indicates the excitation of $\pi-\pi^{*}$ transitions in the bases through impact electron interactions. This does not contradict the results reported above, related to the vibrational excitation, where energy losses involving the bases are essentially absent. In the case of the vibrational part of the energy loss spectra, the interaction of the electrons with the bases is masked by a much more effective interaction of the electrons with the sugar and phosphate moieties. In the electronic excitation region, it is not expected that any DNA component other than the bases will be electronically excited. Therefore, in this energy range, because no other energy losses occur, one can detect the electronic excitation of the conjugated rings of the bases, even though the cross sections are very low.

XPS Results. All ss-DNA samples listed in Table 1 were characterized by XPS. Table 3 reports the results of the quantitative analysis. The relevant regions of the spectra are shown in Figure 6. Assignments of the peaks are presented in Table 4. Atoms are labeled as presented in Figure 7.

For the detailed study, three ss-DNA samples are particularly interesting, specifically those containing only a single base type: samples ss-poly(C), ss-poly(A), and ss-poly(T). The main differences among the XP spectra of ss-poly(C), ss-poly(A), and ss-poly(T) are seen in the $\mathrm{N} 1 \mathrm{~s}$ region (Figure 6a). The $\mathrm{N} 1 \mathrm{~s}$ region of the cytosine-base oligomer is composed of two peaks centered at 398.6 and $400.1 \mathrm{eV}$ : peak 1 is assigned to conjugated $\mathrm{N}\left(\mathrm{sp}^{2}\right)$, and peak 2 has contributions from the amine group $-\mathrm{NH}_{2}$ and nonconjugated $\mathrm{N}\left(\mathrm{sp}^{3}\right)$. The area of peak 2 is twice the area of peak 1. The $\mathrm{N} 1 \mathrm{~s}$ region of ss-poly(A) is also composed of two peaks, centered at 399.0 and $400.2 \mathrm{eV}$, with the same assignments as for $\mathrm{ss}-\operatorname{poly}(\mathrm{C})$ (in this case, the area of peak 1 is 1.5 times the area of peak 2). This region also presents an extra peak at $401.4 \mathrm{eV}$ assigned to $\mathrm{NH}_{3}{ }^{+}$. In sspoly $(\mathrm{T})$, the $\mathrm{N} 1 \mathrm{~s}$ region contains a single peak centered at 400.0 $\mathrm{eV}$ that is attributed to $\mathrm{N}-(\mathrm{C}=\mathrm{O})-\mathrm{N}$. This peak could include an extra component at lower binding energies. The presence of two peaks in the $\mathrm{N}$ 1s region of thymine adsorbed on gold surfaces has been reported before. ${ }^{29}$ In the earlier studies, the component shifted to lower binding energies was attributed to the interaction between nitrogen $\mathrm{N} 3$ of thymine and the substrate. However, in the present case, this type of interaction cannot be inferred from the $\mathrm{N}$ 1s region of this spectrum.

Another important feature that strongly confirms the presence of the adsorbed oligomers on gold is the $\mathrm{P} 2 \mathrm{p}$ region (Figure 6b). Despite the poor signal-to-noise ratio, it is possible to detect a peak around $133.8 \mathrm{eV}$ associated with phosphorus (The $\mathrm{P} 2 \mathrm{p}$ peak is a doublet because of spin-orbit splitting, $\triangle \mathrm{BE}=0.87 \mathrm{eV}^{30}$ ). Lee et al. reported a peak centered at $133.9 \mathrm{eV}$ for pure DNA monolayers deposited on gold and proposed that it arises from nonthiol interactions of the DNA polyanions with the gold substrate. ${ }^{34}$ However, this binding energy is lower than that reported for phosphoric acid ( $\mathrm{BE}$ of $\mathrm{P} 2 \mathrm{p}_{3 / 2}$ in $\mathrm{H}_{3} \mathrm{PO}_{4}=135.2 \mathrm{eV}^{30}$ ), being closer to the $\mathrm{BE}$ of phosphorus in sodium phosphate $\left(\mathrm{NaH}_{2} \mathrm{PO}_{4}\right.$, $134-134.2 \mathrm{eV})$. In fact, sodium is detected in some samples but not in all of them. For example, it is missing in the cases of ss-poly(T) and ss-CGAC. Samples rich in $\mathrm{Na}^{+}$(all of the ds-DNA samples) also present a chlorine peak, indicating that salt is present. In these samples, the $\mathrm{O} 1 \mathrm{~s}$ region also contains a component at high binding energies that can be assigned to water (Figure 6d). In some samples, the amount of sodium is much lower than the amount of phosphorus; hence, it is not enough to ensure neutrality. Because no other 
TABLE 3: Quantitative XPS Elemental Analysis Results for All of the Samples ${ }^{a}$

\begin{tabular}{|c|c|c|c|c|c|c|c|}
\hline $\begin{array}{c}\text { XPS } \\
\text { region }\end{array}$ & ss-poly $(\mathrm{C})$ & ss-poly(A) & ss-poly(T) & ss-GTA-OH & ss-GAT & ss-GCAT & ss-CGAC \\
\hline $\mathrm{C} 1 \mathrm{~s}$ & 39.5 & 40.9 & 39.5 & 40.9 & 43.8 & 40.7 & 45.2 \\
\hline $\mathrm{N}$ 1s & 6.9 & 7.4 & 5.4 & 8.1 & 10.7 & 8.8 & 6.6 \\
\hline P $2 p$ & 1.4 & 0.9 & 1.4 & 1.6 & 2.1 & 1.4 & 1.0 \\
\hline $\mathrm{Au} \mathrm{4f}$ & 19.2 & 34.8 & 38.2 & 25.6 & 19.6 & 27.6 & 21.5 \\
\hline $\mathrm{Na} 1 \mathrm{~s}$ & 3.6 & 1.0 & $b$ & 0.2 & 0.1 & 0.2 & $b$ \\
\hline
\end{tabular}

${ }^{a}$ Spectra were acquired with $\mathrm{Al} \mathrm{K} \alpha$ radiation at $\mathrm{TOA}=90^{\circ} .{ }^{b}$ Not detected.
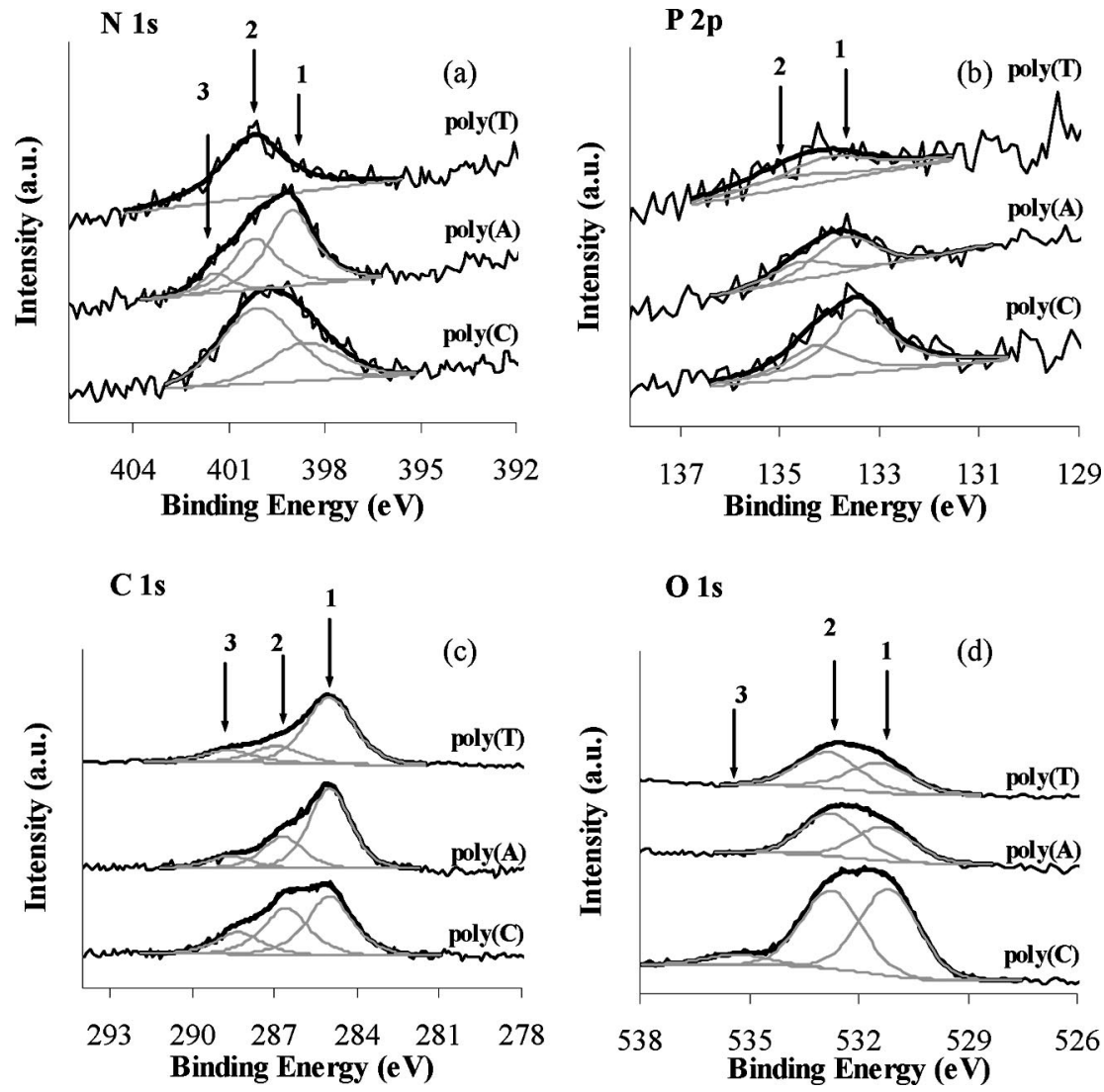

Figure 6. XP spectra of single strands of ss-poly(C), ss-poly(A), and ss-poly(T): (a) N 1s, (b) P 2p with $\Delta \mathrm{BE}=0.87 \mathrm{eV}$, (c) C 1s, and (d) O 1s. Spectra were acquired with $\mathrm{Al} \mathrm{K \alpha}$ radiation at TOA $=90^{\circ}$. Source satellites were subtracted. For peak assignments, see Table 4.

candidate for counterion was detected, we can conclude that the large exchange should have been with hydrogen.

The $\mathrm{C} 1 \mathrm{~s}$ regions were fitted with a minimum of three components (Figure 6c), where each component was the sum of several contributions. Peak 1, centered at $285 \mathrm{eV}$, includes aliphatic carbons of the mercapto-propane terminal group $-\left(\mathrm{CH}_{2}\right)_{3}-\mathrm{SH}$, carbons of the sugar group, and carbons of aliphatic contamination. All of these contributions are common to all samples. In ss-poly(T), peak 1 also contains components attributed to carbons of the thymine base, namely, the methyl group and the aromatic carbon C5. Single-stranded poly(C) also exhibits a contribution from the aromatic carbon C5. Peak 2 of ss-poly(A), centered at $286.7 \mathrm{eV}$, has a strong contribution from carbon bound to nitrogen in adenine, in addition to $\mathrm{C}-\mathrm{O}$ bonds of the sugar groups and sugar-phosphate bonds that, obviously, are present in all samples. The peak centered at higher binding energies, between 288.3 and $288.7 \mathrm{eV}$ (peak 3), is assigned to carbonyl groups in thymine and cytosine bases that are not present in ss-poly(A).
The $\mathrm{O}$ 1s regions were fitted with two components (Figure $6 \mathrm{~d}$ ): One, at $531.3 \pm 0.2 \mathrm{eV}$, is assigned to the oxygen present in the bases and sugars. The other, at $532.7 \pm 0.2 \mathrm{eV}$, is assigned to the backbone phosphate group. In the samples of ss-poly(C), there is a third component, around $535.4 \pm 0.1 \mathrm{eV}$, that is assigned to water, as mentioned above.

Sulfur, in principle, is at the same level as gold because it binds directly to it. However, the detection of sulfur is not obvious, first because it is located at the $\mathrm{Au}-\mathrm{CH}_{3}$ interface, i.e., deep in the layer; second because its photoionization cross section is very low compared to that of $\mathrm{Au} 4 \mathrm{f}$; and finally because its atomic density is much lower than the gold atomic density. In ss-DNA, traces of sulfur can be detected [samples ss-GTA-OH, ss-poly(C), ss-GCAT, and ss-CGAC]; the S 2 $\mathrm{p}_{3 / 2}$ peak is centered at $161.4 \pm 0.4 \mathrm{eV}$ (not shown), which is typical for sulfur bound to a gold surface.

The thicknesses of the different ss-DNA samples [ss-poly(C), ss-poly(A), and ss-poly(T)] adsorbed on Au were estimated from the quantitative XPS results. The estimations were based on 
TABLE 4: Corrected Binding Energies (BEs) (eV) ${ }^{a}$ and Assignments ${ }^{b, c}$

\begin{tabular}{|c|c|c|c|c|c|c|c|}
\hline region & position & ss-poly(C) & ss-poly(A) & ss-poly $(\mathrm{T})$ & literature ${ }^{29-35}$ & & assignment \\
\hline \multirow[t]{3}{*}{$\overline{\mathrm{N}} 1 \mathrm{~s}$} & 1 & 398.6 & 399.0 & & $399.0-399.3$ & & $-\mathbf{N}=$ conjugated \\
\hline & 2 & 400.1 & 400.2 & 400.2 & $399.9-401.0$ & & $-\mathbf{N H}_{2}$ and $>\mathbf{N}-($ in $\mathrm{C}$ and $\mathrm{A}) ; \mathbf{N}-(\mathrm{CO})-\mathbf{N}(\mathrm{T})$ \\
\hline & 3 & & 401.4 & & & & $-\mathrm{NH}_{3}^{+}$ \\
\hline & 2 & 134.2 & 134.6 & 134.9 & +0.87 & $\mathrm{P} 2 \mathrm{p}_{1 / 2}$ & \\
\hline \multirow[t]{2}{*}{$\mathrm{C} 1 \mathrm{~s}$} & 1 & 285 & 285 & 285 & $284.7-286.2$ & & $\begin{array}{l}-\mathbf{C}-\mathbf{C}-(\text { deoxyribose }) ;-\mathbf{C}=(\mathrm{C} 5 \text { in } \mathrm{C}) ;-\mathbf{C H}(\text { alkyl } \\
\left.\text { chain }-\mathbf{C}_{3} \mathrm{SH} \text {, methylgroup in } \mathrm{T} \text { and aliphatic contamination }\right) \text {; } \\
(\mathrm{CO})-\mathbf{C}=(\mathrm{C} 5 \text { in } \mathrm{T})\end{array}$ \\
\hline & 3 & 288.3 & 288.6 & 288.7 & $287.8-289.1$ & & $\begin{array}{l}\mathrm{C}-\mathrm{NH}_{2}(\mathrm{C} 6 \text { in } \mathrm{A} \text { and } \mathrm{C} 4 \text { in } \mathrm{C}) ; \mathrm{N}-(\mathrm{CO})-\mathrm{C}(\mathrm{C} 4 \text { in } \mathrm{T}) \\
\mathrm{N}-(\mathbf{C O})-\mathrm{N}(\mathrm{C} 2 \text { in } \mathrm{C} \text { and } \mathrm{T})\end{array}$ \\
\hline \multirow[t]{2}{*}{$\mathrm{O} 1 \mathrm{~s}$} & 1 & 531.2 & 531.3 & 531.4 & 531.1 & & $\begin{array}{l}\mathrm{C}-\mathrm{O}-\mathrm{C} \text { cyclic ether (deoxyribose); } \mathrm{N}-(\mathrm{CO})-\mathrm{X}(\mathrm{X}=\mathrm{C} \text { or } \mathrm{N}) \\
\text { (bases) }\end{array}$ \\
\hline & 2 & 532.7 & 532.7 & 532.8 & $532-534$ & & $\mathrm{PO}_{4}^{-}$(backbone) \\
\hline $\mathrm{Na} 1 \mathrm{~s}$ & 1 & 1071.1 & 1071.2 & & & & counterion \\
\hline \multirow[t]{2}{*}{$\mathrm{Cl} 2 \mathrm{p}$} & 1 & 198.2 & & & & Cl $2 \mathrm{p}_{3 / 2}$ & \\
\hline & 2 & 199.8 & & & & Cl $2 \mathrm{p}_{1 / 2}$ & \\
\hline
\end{tabular}

${ }^{a}$ Using $\mathrm{C} 1 \mathrm{~s}=285 \mathrm{eV}$ as a reference. Error $= \pm 0.2 \mathrm{eV} .{ }^{b} \mathrm{C}$, cytosine; A, adenine; T, thymine. ${ }^{c}$ For atom positions, see Figure 7.<smiles></smiles>

Adenine<smiles></smiles>

Guanine

Pujines

Figure 7. Structures of the four bases of DNA.

the $\mathrm{C}$ 1s/Au 4f, $\mathrm{N} \mathrm{1s/Au} \mathrm{4f,} \mathrm{and} \mathrm{P} 2 \mathrm{p} / \mathrm{Au}$ atomic ratios $4 \mathrm{f}$ for two different TOAs $\left(90^{\circ}\right.$ and $\left.30^{\circ}\right)$. Two models were tested: a homogeneous, continuous monolayer of constant thickness completely covering the substrate and an island-like layer. The first model did not fit at all of the experimental data, but the second model, although very schematic, can describe these adsorbed layers quite well.

Equation 1 was fitted to the experimental ratios

$$
\frac{\mathrm{X}}{\mathrm{Au}}=\frac{n_{\mathrm{X}}}{n_{\mathrm{Au}}} \frac{f\left[1-\exp \left(-\frac{l}{\lambda_{\mathrm{X}} \sin \theta}\right)\right]}{(1-f)+f \exp \left(-\frac{l}{\lambda_{\mathrm{Au} 4 \mathrm{f}} \sin \theta}\right)}
$$

where $\mathrm{X}$ is $\mathrm{C} 1 \mathrm{~s}, \mathrm{~N} 1 \mathrm{~s}$, or $\mathrm{P} 2 \mathrm{p}$. The value $\theta$ is the takeoff angle $\left(\mathrm{TOA}=90^{\circ}\right.$ or $30^{\circ}$ ), and $\lambda$ represents the photoelectron inelastic mean free paths of C 1s, N 1s, P 2p, and Au 4f. The values of $\lambda$ were determined by Wagner's expression $\lambda=k E^{m}$, where $E$ is the photoelectron kinetic energy and $k$ and $m$ are parameters attributed to DNA, equal to 0.130 and 0.792 , respectively. ${ }^{36}$ The value $n_{\mathrm{X}} / n_{\mathrm{Au}}$ is the atomic density ratio, where $n_{\mathrm{X}}$ and $n_{\mathrm{Au}}$ are the carbon, nitrogen, or phosphorus density in the film and the gold density in the substrate, respectively. The thickness, $l$, and the covered surface fraction, $f$, were fitted parameters. For the three monolayers, $/$ was found to be about 6,5 , and $5 \mathrm{~nm}$ and $f$ to be $0.9,0.7$, and 0.8 for the monolayers made from ss-poly(C), ss-poly(A), and ss- poly(T), respectively. Nevertheless, eq 1 does not take into account shadow effects and heterogeneous distributions of the elements $\mathrm{P}$ and $\mathrm{N}$ as<smiles></smiles><smiles>CC1=CNC2(C)CNC(=O)N12</smiles>

Thymine

Pyrimidines should be the case for highly organized layers and the obtained values should be taken as merely qualitative.

The estimated thicknesses of $\sim 5 \mathrm{~nm}$ indicates that the singlestranded oligonucleotides of 26 bases either are not stretched or are oriented away from the surface normal, because the lengths of those strands when unfolded are on the order of 8 nm. ${ }^{37}$

The monolayer of ss-poly(A) seems to be less packed than the monolayers of the other oligomers, confirming previous observations. ${ }^{37}$ Single-stranded poly $(\mathrm{C})$, even though a shorter oligomer with only 15 of cytosine bases, provides a well-covered surface, similarly to the other oligomers, and seems to be in an upright position, taking into account the estimated thickness of $6 \mathrm{~nm}$.

\section{Discussion}

The vibrational HREEL spectra exhibit exceptionally sharp peaks, indicating that the monolayers are uniform and wellordered. However, these results are not in complete agreement with the XPS data from which it was concluded that the coverage of the surface was lowest for ss-poly(A) $(\sim 70 \%)$, intermediate for ss-poly(T) $(\sim 80 \%)$, and highest for ss-poly $(\mathrm{C})$ ( $\sim 90 \%)$. The last value is the value expected for a well-ordered layer presenting a compact hexagonal structure. This discrepancy between the conclusions based on the two techniques might arise from the fact that each of the techniques is sensitive to a different region of the monolayer. Whereas HREELS probes mainly the end of the molecules facing the vacuum, as most processes are 
due to impact mechanisms, XPS probes the coverage on the gold itself. It is quite possible that, although the layer is not dense and fully ordered near the substrate, the long molecules arrange themselves in such a way that their tails, facing the vacuum, are well-ordered. This effect is expected especially in the case of single strands that are flexible.

All of the vibrational HREEL spectra are dominated by features related to the phosphate and deoxyribose units of the backbone, with some minor contribution from the bases. The most intense bands are located around $800 \mathrm{~cm}^{-1}$ and around $1080 \mathrm{~cm}^{-1}$. The first is assigned to the out-of-plane deformation modes of $\mathrm{CH}$ in the bases mixed with the $\mathrm{P}-\mathrm{O}-\mathrm{C}$ symmetric stretching modes; the second is assigned to the phosphate stretching modes and the $\mathrm{C}-\mathrm{O}-\mathrm{C}$ unit of the chain. Excitation of the $\mathrm{C}=\mathrm{O}$ stretching mode can be observed in all of the spectra except for those where adenine is the main component. The dependence of the intensity of the bands on the electron kinetic energy (Figure 4B) shows that the main peaks have an impact or hybrid character; that is, energy is lost either by direct impact of the electrons with the specific group on the surface or by impact and electron-dipole interaction. One can conclude that incident electrons are mostly backscattered from the backbone of the DNA strand. The $\mathrm{C}=\mathrm{O}$ stretching mode in the bases has a striking dipolar character confirmed by the decrease of the differential cross sections with increasing electron incident energy. This observation confirms that electrons excite the bases mainly by a long-range interaction.

The strong interaction between the electrons and the phosphate groups is surprising if one assumes that the phosphates are negatively charged. However, the XPS results indicate that most of the phosphates cannot be negatively charged, because in some samples, the number of cations $\left(\mathrm{Na}^{+}\right)$is lower than the number of phosphorus atoms. That is, it seems that the phosphate groups become neutral as a result of hydrogen association. These results are consistent with earlier studies in which cations in self-assembled monolayers of DNA were not observed. ${ }^{38}$ This effect might result from the crowding of the DNA when self-assembled. The interaction might affect the $\mathrm{p} K_{\mathrm{a}}$ of the phosphate group, resulting in the transformation of these groups into the protonated form, instead of the ionic one. This phenomenon of a crowding-induced change in $\mathrm{p} K_{\mathrm{a}}$ is wellknown in proteins ${ }^{39}$ and other systems. ${ }^{40}$

The peaks of the thermalized electrons localized at the end of the HREEL spectra indicate that the electron affinities of the samples are close to zero, that is, the bottom of the conduction band is near the vacuum level. It is important to emphasize that this statement is valid only if one considers vertical electron affinity, that is, the situation in which the molecules do not reorganize themselves as a result of the interaction with the extra electron. It is possible that the adiabatic electron affinity is positive, or that the conduction band for the system, after being reorganized, is below the vacuum level.

These results also confirm previous studies in which it was proposed that DNA, when organized as a self-assembled monolayer, is not completely charged. Also, the finding that low-energy electrons mainly interact with the backbone of the DNA should indicate that damage occurring during interactions with electrons is mainly localized on the DNA backbone. ${ }^{41}$

Supporting Information Available: Experimental methods, XP spectra, table of corrected binding energies, structures of the four bases of DNA, table of estimated thicknesses and covered surface fractions, and additional references. This material is available free of charge via the Internet at http:// pubs.acs.org.

\section{References and Notes}

(1) Boudaïffa, B.; Cloutier, P.; Hunting, D.; M. Huels, A.; Sanche, L. Science 2000, 287, 1658-1660.

(2) Naaman, R.; Sanche, L. Chem. Rev. 2007, 107, 1553-1579.

(3) Sanche, L. Eur. Phys. J. 2005, 35, 367-390.

(4) Simons, J. Acc. Chem. Res. 2006, 39, 772-779.

(5) Pan, X.; Sanche, L. Chem. Phys. Lett. 2006, 421, 404-408.

(6) Levesque, P. L.; Michaud, M.; Sanche, L. Nucl. Instrum. Methods Phys. Res. B 2003, 208, 225-230.

(7) Ptasiñska, S.; Sanche, L. Phys. Chem. Chem. Phys. 2007, 9, 17301735.

(8) Bald, I.; Kopyra, J.; Illenberger, E. Angew. Chem., Int. Ed. 2006, 45, 4851-4855.

(9) Denifl, S.; Ptasinska, S.; Cingel, M.; Matejcik, S.; Scheier, P.; Märk, T. Chem. Phys. Lett. 2003, 377, 74-80.

(10) Ptasinska, S.; Sanche, L. J. Chem. Phys. 2006, 125, 144713.

(11) Swarts, S. G.; Gilbert, D. C.; Sharma, K. K.; Razskazovskiy, Y.; Purkayastha, S.; Naumenko, K. A.; Bernhard, W. A. Radiat. Res. 2007, 168, 367-381.

(12) Ptasinska, S.; Denifl, S.; Scheier, P.; Illenberger, E.; Märk, T. D. Angew.Chem. Int.Ed. 2005, 44, 6941-6943.

(13) Ptasinska, S.; Denifl, S.; Mroz, B.; Probst, M.; Grill, V.; Illenberger, E.; Scheier, P.; Märk, T. D. J. Chem. Phys. 2005, 123, 124302.

(14) Denifl, S.; Ptasinska, S.; Probst, M.; Hrusak, J.; Scheier, P.; Märk, T. D. J. Phys. Chem. A 2004, 108, 6562-6569.

(15) Abdoul-Carime, H.; Gohlke, S.; Illenberger, E. Phys. Rev. Lett. 2004, $92,168103$.

(16) Abouaf, R.; Pommier, J.; Dunet, H. Int. J. Mass Spectrom. 2003, 226, 397-403.

(17) Hanel, G.; Gstir, B.; Denifl, S.; Scheier, P.; Probst, M.; Farizon, B.; Farizon, M.; Illenberger, E.; Märk, T. D. Phys. Rev. Lett. 2003, 90, 188104.

(18) ICRU Report 31; International Commission on Radiation Units and Measurement: Washington, DC,1979.

(19) Ray, S. G.; Daube, S. S.; Naaman, R. Proc. Nat. Acad. Sci. 2005, $102,15-19$.

(20) Ray, S. G.; Daube, S. S.; Cohen, H.; Naaman, R. Isr. J. Chem., in press.

(21) Cai, Z.; Dextraze, M. E.; Cloutier, P.; Hunting, D.; Sanche, L. J. Chem. Phys. 2006, 124, 024705.

(22) Solomun, T.; Sturm, H. J. Phys. Chem. B 2007, 111, 1063610638.

(23) Ibach, H.; Mills, D. L. Electron Energy Loss Spectroscopy and Surface Vibrations; Academic Press:New York, 1982, and references therein.

(24) Botelho do Rego, A. M.; Rei Vilar, M.; Lopes da Silva, J. J. Electron Spectrosc. Relat. Phenom. 1997, 85, 81.

(25) Socrates, G. Infrared Characteristic Group Frequencies, 2nd ed.; John Wiley \& Sons: Chichester, U.K., 1994.

(26) Santamaria, R.; Charro, E.; Zacarias, A.; Castro, M. J. Comput. Chem. 1999, 20, 511-530.

(27) Dannetun, P.; Schott, M.; Rei Vilar, M. Thin Solid Films 1996, $286,321-329$.

(28) Botelho do Rego, A. M.; Rei Vilar, M.; Pellegrino, O. Macromolecules 2001, 34, 4987 .

(29) Beamson,G.; Briggs,D. High Resolution XPS of Organic Polymers: The Scienta ESCA300 Database; John Wiley \& Sons: New York, 1992.

(30) Wagner, C. D.; Naumkin, A. V.; Kraut-Vass, A.; Allison, J. W.; Powell, C. J.; Rumble, J. R. NIST X-ray Photoelectron Spectroscopy Database, NIST Standard Reference Database 20, version 3.3 (web version); National Institute of Standards and Technology (NIST): Gaithersburg, MD, 2003; available at http://srdata.nist.gov/xps/ (accessed in 2007).

(31) Saprigin, A. V.; Thomas, C. W.; Dulcey, C. S., Jr.; Spector, M. S. Surf. Interface Anal. 2004, 36, 24-32.

(32) Roelfs, B.; Bunge, E.; Schröter, C.; Solomun, T.; Meyer, H.; Nichols, R. J.; Baumgärtel, H. J. Phys. Chem. B 1997, 101, 754-765, and references therein.

(33) May, C. J.; Canavan, H. E.; Castner, D. G. Anal. Chem. 2004, 76, 1114-1122.

(34) Lee, C. Y.; Gong, P.; Harbers, G. M.; Grainger, D. W.; Castner, D. G.; Gamble, L. J. Anal. Chem. 2006, 78, 3316-3325.

(35) Laiho, T.; Leiro, J. A. Appl. Surf. Sci. 2006, 252, 6304-6312.

(36) Tanuma, S.; Powell, C. J.; Penn, D. R. Surf. Interface Anal. 1994, $21,165-176$ 
(37) Nogues, C.; Cohen, S. R.; Daube, S.; Apter, N.; Naaman, R. J. Phys. Chem. B 2006, 110, 8910-8913.

(38) Ray, S. G.; Cohen, H.; Naaman, R.; Rabin, Y. J. Am. Chem. Soc. 2005, 127, 17138-17139.

(39) (a) See, for example: Hallgren, N. K.; Busby, E. R.; Mommsen, T. P. J. Comp. Physiol. B 2003, 173, 591-599. (b) Mahmmoud, Y. A.; Cornelius, F. Biophys. J. 2002, 82, 1907-1919.
(40) (a) Snowden, T. S.; Bisson, A. P.; Anslyn, E V. Bioorg. Med. Chem. 2001, 9, 2467-2478. (b) Parker, J. C.; Colclasure, G. C. Mol. Cell. Biochem. 1992, 114, 9-11.

(41) Barrios, R.; Skurski, P.; Simons, J. J. Phys. Chem. B 2002, 106, 7991-7994.

JP8008207 